\title{
A gestão da concessão florestal no estado do Pará
}

\author{
Management of the forest concession in the state of Pará \\ Gestión de la concesión forestal en el estado do Pará
}

Recebido: 23/12/2021 | Revisado: 30/12/2021 | Aceito: 03/01/2022 | Publicado: 04/01/2022

\author{
Cintia da Cunha Soares \\ ORCID: https://orcid.org/0000-0002-1654-3347 \\ Universidade Federal do Pará, Brasil \\ E-mail: cintiacsoares@gmail.com \\ Maria das Graças Ferraz Bezerra \\ ORCID: https://orcid.org/0000-0002-0597-3165 \\ Museu Paraense Emílio Goeldi, Brasil \\ E-mail:mgferrazb@gmail.com
}

\begin{abstract}
Resumo
O presente trabalho teve por objetivo descrever o desempenho do órgão gestor do estado do Pará na implementação da concessão florestal; a partir do monitoramento dos contratos de concessão florestal nas florestas públicas denominadas como Conjunto de Glebas Mamuru-Arapiuns e Floresta Estadual do Paru. Os estudos foram realizados em florestas públicas, no estado do Pará, na mesorregião do Baixo Amazonas, em 09 contratos de concessão florestal. Essa pesquisa baseou-se em instrumento de cunho bibliográfico e documental, a partir de trabalhos científicos e documentos oficiais fornecidos pelo Instituto de Desenvolvimento Florestal e da Biodiversidade. Dentre os principais resultados temos o pioneirismo do estado do Pará como o único ente federativo a implantar concessão florestal em florestas não destinadas ou florestas do tipo B, desde a criação da lei de gestão de florestas públicas. Para a efetiva gestão e monitoramento o órgão gestor empenhou-se na elaboração de normativas, diretrizes, notas técnicas, pareceres técnicos que visam orientar os concessionários ao cumprimento dos contratos de concessão florestal. De forma geral, mesmo diante de inúmeras situações adversas enfrentadas, a atuação do IDEFLOR-Bio na gestão tem como propósito garantir que a concessão florestal se mantenha como uma política florestal efetiva e eficiente.
\end{abstract}

Palavras-chave: Concessão florestal; Florestas públicas; Unidade de conservação; Recurso florestal.

\begin{abstract}
The present work aimed to describe the performance of the managing body of the state of Pará in the implementation of forest concessions; based on the monitoring of forest concession contracts in public forests known as the MamuruArapiuns Group of Glebas and Paru State Forest. The studies were carried out in public forests, in the state of Pará, in the mesoregion of Baixo Amazonas, in 09 forest concession contracts. This research was based on bibliographic and documental instruments, based on scientific papers and official documents provided by the Institute of Forestry and Biodiversity Development. Among the main results we have the pioneering role of the state of Pará as the only federative entity to implement forest concessions in non destined forests or type B forests, since the creation of the public forest management law. For the effective management and monitoring, the managing body has endeavored in the elaboration of norms, guidelines, technical notes, technical opinions that aim to guide the concessionaires to the fulfillment of the forest concession contracts. In general, even in the face of numerous adverse situations, IDEFLOR-Bio's performance in the management has the purpose of guaranteeing that the forest concession is maintained as an effective and efficient forest policy.
\end{abstract}

Keywords: Forest concession; Public forests; Conservation unit; Forest resource.

\section{Resumen}

El objetivo de este estudio fue describir el desempeño del órgano gestor del estado de Pará en la implementación de las concesiones forestales; a partir del seguimiento de los contratos de concesión forestal en los bosques públicos conocidos como el Grupo Mamuru-Arapiuns de Glebas y el Bosque Estatal de Paru. Los estudios se realizaron en bosques públicos, en el estado de Pará, en la mesoregión del Bajo Amazonas, en 09 contratos de concesión forestal. Esta investigación se basó en un instrumento bibliográfico y documental, basado en artículos científicos y documentos oficiales proporcionados por el Instituto de Desarrollo Forestal y de la Biodiversidad. Entre los principales resultados tenemos el espíritu pionero del Estado de Pará como único ente federativo en implementar concesiones forestales en bosques no asignados o de tipo B, desde la creación de la ley de gestión forestal pública. Para una gestión y un seguimiento eficaces, el órgano de gestión ha trabajado mucho en la elaboración de reglamentos, directrices, notas técnicas y dictámenes técnicos destinados a orientar a los concesionarios en el cumplimiento de los contratos de concesión forestal. En general, 
incluso ante numerosas situaciones adversas, la actuación de IDEFLOR-Bio en la gestión tiene como objetivo asegurar el mantenimiento de la concesión forestal como política forestal eficaz y eficiente.

Palabras clave: Concesión forestal; Bosques públicos; Unidad de Conservación; Recurso forestal.

\section{Introdução}

Quando criada em 2006, a Lei de Gestão de Florestas Públicas para produção Sustentável (LGFP) descentralizava aos estados e municípios, a competência para gerenciamento de florestas públicas de suas respectivas jurisdições. No âmbito do Estado do Pará, por meio da Lei Estadual n ${ }^{\circ}$ 6.963, de 16 de abril de 2007, criava-se o Instituto de Desenvolvimento Florestal do Estado do Pará - IDEFLOR, entidade de direito público, constituída sob a forma de autarquia, com autonomia técnica, administrativa e financeira, tendo por finalidade exercer a gestão de florestas públicas para produção sustentável e a gestão da política estadual para produção e desenvolvimento da cadeia florestal no Estado do Pará.

Dessa forma, a descentralização consentida pela Lei de Gestão de Florestas Públicas, age como um potencial instrumento de democratização de decisões, assim como traz a possibilidade de maior eficiência na implantação das políticas públicas, uma vez que transferiu aos estados, as atribuições para autorizar e fiscalizar a exploração florestal em áreas sob sua jurisdição (CARDOSO, 2018). Considerando a descentralização de competências, coube ao Ideflor:

\section{$I-\ldots$}

II - exercer a função de órgão gestor de florestas públicas estaduais para produção sustentável, em conformidade com a legislação federal e em articulação com os demais órgãos estaduais de desenvolvimento;

III - elaborar e executar, em articulação com os demais órgãos estaduais e federais competentes, todos os procedimentos e regulamentos necessários à realização, ao controle e à fiscalização da concessão de florestas públicas para produção sustentável, de domínio estadual, em conformidade com a legislação estadual e federal pertinente; $I V$ - propor e apoiar o órgão ambiental do Estado na criação de florestas públicas estaduais para produção sustentável, nos termos estabelecidos pela legislação federal e estadual;

$V$ - elaborar e executar, em articulação com os demais órgãos estaduais e federais pertinentes, todos os procedimentos necessários ao aproveitamento e ao uso dos recursos florestais das florestas públicas estaduais para produção sustentável em conformidade com a legislação estadual e federal pertinente;

$V I-\ldots$

O governo do Pará por meio da Lei Estadual n ${ }^{\circ} 8.096$, de $1^{\circ}$ de janeiro de 2015, realizou uma reforma administrativa, e o então, IDEFLOR tornou-se Instituto de Desenvolvimento Florestal e da Biodiversidade do Estado do Pará - IDEFLOR-Bio, agregando às suas competências, a execução da Gestão das Unidades de Conservação do Estado relativas à sua proposição, criação, implementação e monitoramento, dentre outras funções de importância equivalente. De forma análoga aos órgãos federais, o IDEFLOR-Bio acumulou funções equivalentes as do Instituto Chico Mendes de Conservação da Biodiversidade (ICMBio) e Serviço Florestal Brasileiro (SFB). Com estas alterações, o IDEFLOR-Bio integrou, no âmbito do estado e na esfera de sua competência, o Sistema Nacional do Meio Ambiente - SISNAMA e o Sistema Estadual de Meio Ambiente e Recursos Hídricos - SISEMA.

A primeira floresta pública a ser concedida no Brasil foi a Floresta Nacional de Jamari, pelo SFB, no Estado de Rondônia, com 96 mil hectares de florestas destinados para concessão florestal (MUNIZ; PINHEIRO, 2019). Todavia, o Pará tornou-se pioneiro entre os estados a conceder florestas públicas e o primeiro, entre os entes federativos, a conceder florestas em áreas de florestas públicas não destinadas, o qual concedeu 150.956, 95 há no conjunto de glebas Mamuru-Arapiuns, sendo considerado um marco na política territorial e florestal do Estado do Pará, dado que foi necessário e fundamental definir uma 
estratégia de ordenamento territorial para o atendimento da demanda dos atores sociais da região, previamente a definição das áreas a serem concedidas.

O conjunto de glebas Mamuru-Arapiuns com 1.122.054,978 ha, um território com enorme potencial florestal, sofria com as pressões de ocupação irregular e exploração ilegal de recursos florestais foi considerado um grande desafio para Órgão Gestor, pois para conceder as florestas para produção madeireira, seria necessário "organizar o território", isto é, ao tempo que os estudos de campo foram sendo realizados, iniciavam as discussões, reuniões, consultas e audiências públicas para previamente regularizar terras, definindo áreas para conservação, para gestão florestal, para comunidades locais, para enfim, definir as áreas para concessão florestal.

Problemas relatados por Santana et al., (2011), como falta de regularização fundiária, demora na aprovação e liberação dos planos de manejo solicitados pelas madeireiras e autorização da extração madeireira, deficiência na fiscalização da madeira em trânsito, poderiam ser minimizados com as concessões florestais, que além de aumentar a oferta de madeira, contribuiria para regularização fundiária, monitoramento e fiscalização para minimizar comércio de madeira ilegal na região do MamuruArapiuns.

Em pesquisa realizada em 2008, Melo Junior et al. (2013) constataram cerca de 3.070 pessoas vivendo nas 20 comunidades estudadas. Para essas pessoas, $36,4 \%$ dos entrevistados acham que a concessão florestal traria problemas fundiários e seria prejudicial para as comunidades. $27,3 \%$ temem que haja perda da biodiversidade e, apenas $9,1 \%$ acreditam que não haveria prejuízo para as comunidades. Outros $27,3 \%$ acham que a concessão iria gerar emprego e traria desenvolvimento à região.

O estado do Pará ao implementar a concessão florestal, cumpriu o art. $6^{\circ}$ da LGFP, ao destinar no Conjunto de Glebas Mamuru-Arapiuns áreas para criação de Projetos de Assentamentos Estaduais, áreas de florestas públicas para uso exclusivo comunitário. O processo de destinação de terras públicas, no conjunto de Glebas Mamuru-Arapiuns, às comunidades locais, consolidou a criação de 07 projetos de assentamentos nas categorias PEAEX e PEAS, que totalizam 293.226,97 hectares para uso exclusivo comunitário (Soares et al., 2017).

Em 2005, o governo do estado elaborou e aprovou o Macrozoneamento Ecológico Econômico (ZEE). E os estudos identificaram a importância ecológica e a existência de extensas áreas devolutas e não destinadas, direcionando à criação de Unidades de Conservação no Norte do Pará. Além disso, outros estudos já apontavam para o risco de grilagens - evidenciado pelo grande número de requerimentos de terra junto ao Instituto de Terras do Pará (ITERPA) - e o avanço do desmatamento nessa região. Dessa forma, o governo do Estado do Pará e instituições parceiras iniciaram as discussões para a criação de Unidades de Conservação Estaduais (Pereira et al., 2020).

Então, baseado no Macrozoneamento Ecológico-Econômico (ZEE) do estado do Pará, instituído pela Lei n 6.745 , de 06 de maio de 2005, e em conformidade com o inciso $1^{\circ}$, art. $4^{\circ}$ da Lei de Gestão de Florestas Públicas (LGFP), ao final de 2006, o Governo do Pará decretou a criação de 04 unidades de conservação na categoria Floresta Estadual (FLOTA), a saber, a floresta estadual do Paru; floresta estadual de Trombetas; floresta estadual de Faro e Floresta estadual do Iriri somando 7. 604. 508, 28 hectares.

A expectativa do governo do Pará ao criar as FLOTAS era contribuir para o desenvolvimento de uma economia florestal manejada no Estado. Em termos específicos, a criação dessas unidades de conservação poderia atrair empresas florestais comprometidas com práticas de manejo florestal sustentável e com responsabilidade socioambiental (Mesquita, 2014), que viessem a se tornar futuras concessionárias do Estado do Pará.

Para tornar a floresta pública habilitada à concessão florestal, alguns requisitos devem ser atendidos e tornaram-se indispensáveis para o avanço de sua implementação, como: dirimir qualquer que seja o conflito existente; não haver sobreposição com área de uso e/ou moradia de comunidades locais, bem como apresentação de Relatório Ambiental Preliminar - RAP para 
as unidades a serem concedidas, com exceção à unidades de conservação na categoria Floresta Estadual - FLOTA, o qual o plano de manejo/gestão da unidade deveria estar devidamente aprovado conforme art. 48 da lei:

Art. 48. As concessões em florestas nacionais, estaduais e municipais devem observar o disposto nesta Lei, na Lei $n^{o}$ 9.985, de 18 de julho de 2000, e no plano de manejo da unidade de conservação.

$\S 1^{\circ} \ldots$

$\S 2^{\circ}$ Os recursos florestais das unidades de manejo de florestas nacionais, estaduais e municipais somente serão objeto de concessão após aprovação do plano de manejo da unidade de conservação, nos termos da Lei $n^{\circ} 9.985$, de 18 de julho de 2000.

As Florestas Estaduais (FLOTAS) do Paru, Trombetas, Faro e Iriri ${ }^{1}$, devido a sua definição legal, que tem como objetivo o uso múltiplo sustentável dos recursos florestais, com ênfase em métodos para exploração sustentável de florestas nativas foram consideradas como habilitadas a concessão florestal estando todas inseridas no primeiro Plano Anual de Outorga Florestal PAOF do Estado do Pará, entretanto, apenas a FLOTA do Paru atendeu a todos os requisitos legais e administrativos e avançou no processo de concessão florestal.

As FLOTAS Trombetas e Faro, apresentavam, até 2018, um contexto territorial de sobreposições com territórios de povos indígenas e quilombolas, solucionados com o redimensionamento dos seus limites, havendo, então, a necessidade de atualização de Plano de Manejo. No caso da FLOTA do Iriri, a mesma ainda não havia aprovado o Plano de Manejo/Gestão. Atendidas essas condições consideradas SINE QUA NON, essas unidades de conservação poderão ser novamente inseridas no PAOF. Dessa maneira, e como resultado, a única Unidade de Conservação na categoria Floresta Estadual com concessão florestal é a FLOTA do Paru, com 332.478,54 ha de florestas concedidas.

Nesse sentido, o presente estudo tem como objetivo, descrever o desempenho do órgão gestor do estado do Pará na implementação da concessão florestal; avaliando a gestão adotada para alcance de resultados, a partir do monitoramento dos contratos de concessão florestal nas florestas públicas denominadas como Conjunto de Glebas Mamuru-Arapiuns e Floresta Estadual do Paru.

\section{Metodologia}

\section{1 Área de Estudo}

Como podemos observar na Figura 1, o conjunto de glebas Mamuru-Arapiuns e a Floresta Estadual do Paru estão localizadas ao Norte do Pará, nas mesorregiões do Baixo Amazonas, onde se concentra o maior bloco de áreas protegidas do Estado, formado por Unidades de conservação federais; Unidades de conservação estaduais; Projetos de assentamentos federais; Projetos de assentamentos estaduais; Territórios quilombolas e Territórios indígenas.

A concessão florestal compõe esse bloco de áreas protegidas nas áreas que permitem essa modalidade de gestão instituída pela Lei Federal n ${ }^{\circ} 11.284 / 2006$, estando presente no conjunto de glebas Mamuru-Arapiuns, na Floresta Estadual (FLOTA) do Paru, sob a gestão do IDEFLOR-Bio e na FLONA Saracá-Taquera, sob a gestão do SFB, somando 616.445,49 ha de florestas concedidas nesta região, sendo o objeto desta pesquisa a concessão florestal sob a gestão do IDEFLOR-Bio que totalizam 483.435,49 ha, distribuídas em 09 unidades de manejo florestal (UMF).

\footnotetext{
${ }^{1}$ A Flota Iriri não tem plano de manejo (gestão), de acordo com PPA 2020 a 2023, deve ser aprovado até 2023.
} 
Figura 1 - Mapa de localização das florestas públicas destinadas no Norte do Pará.

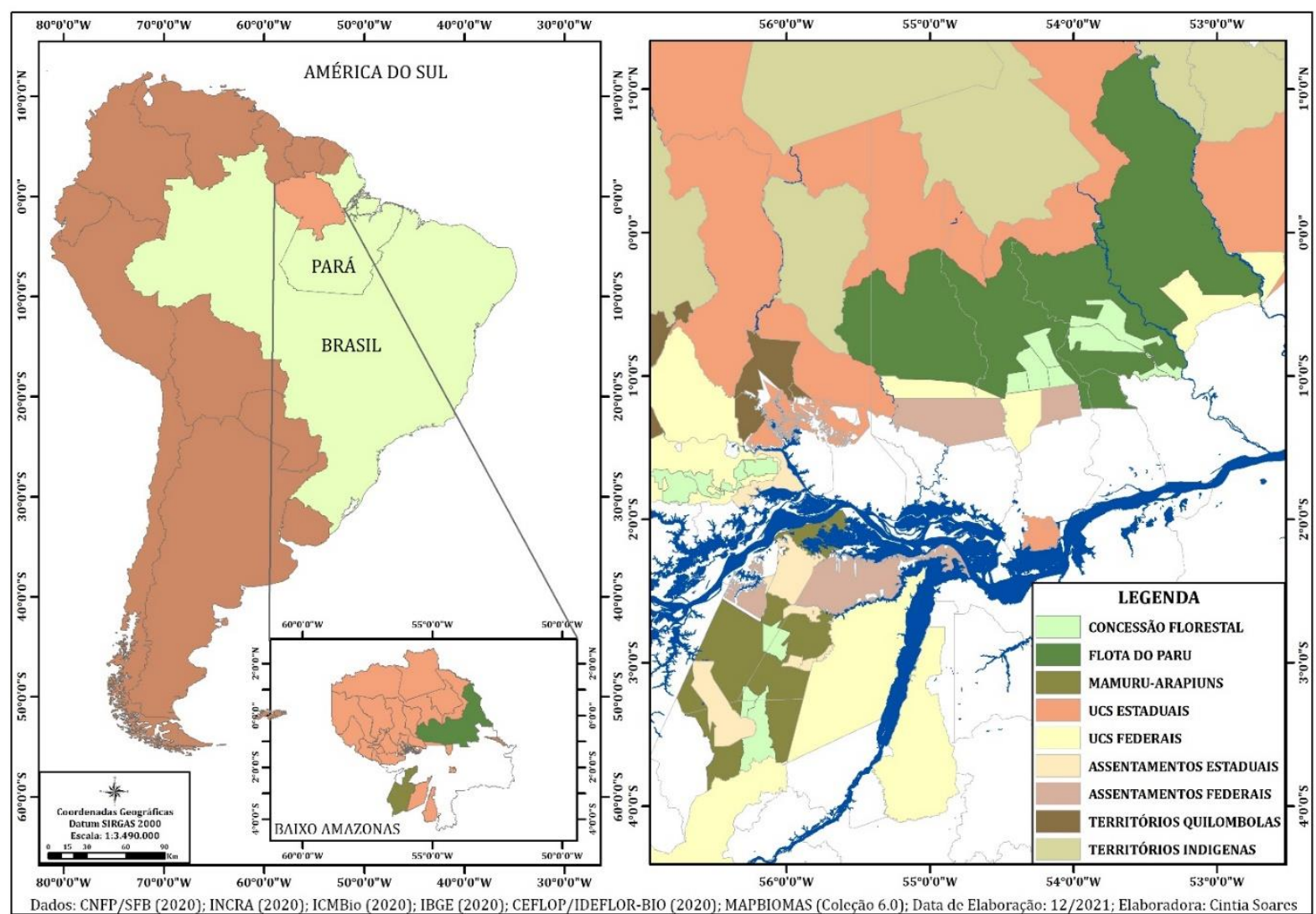

Dados: CNFP/SFB (2020); INCRA (2020. ICMBIO (2020); IBGE (2020); CEFLOP/IDEFLOR-Bio (2020); MAPBIOMAS (Coleção 6.0). Fonte: Elaborado pelos autores.

\subsection{Pesquisa Documental}

Essa pesquisa baseou-se em instrumento de cunho bibliográfico e documental (Gil, 2021), a partir de trabalhos científicos e documentos oficiais fornecidos pelo órgão gestor das florestas públicas do estado do Pará, o Instituto de Desenvolvimento Florestal e da Biodiversidade (IDEFLOR-Bio). Especificamente, o acesso aos documentos institucionais se deu de forma direta, extraída do site do IDEFLOR-Bio e fornecidas a partir do banco de dados da Diretoria de gestão de Florestas Públicas de Produção (DGFLOP), subordinada ao IDEFLOR-Bio.

\section{Resultados e Discussão}

\subsection{Do pioneirismo do estado do Pará na concessão florestal}

Há um processo muito longo entre a definição de áreas que serão inseridas no PAOF e a assinatura do contrato de concessão florestal. Todo processo inicia com a elaboração do Plano Anual de Outorga Florestal - PAOF, documento proposto pelo órgão gestor contendo a descrição de todas as florestas públicas a serem submetidas a processos de concessão no ano em que vigorar.

O primeiro Plano Anual de Outorga Florestal (PAOF) do Estado do Pará apresentado em 2009, trouxe muitas expectativas e estimativas de áreas de concessão e produção madeireira em níveis elevados. Naquele ano, as florestas públicas do Estado do Pará legalmente aptas para concessão florestal totalizam aproximadamente 10,5 milhões de hectares, sendo selecionada 686.255,25 ha como área prioritária no conjunto de glebas Mamuru-Arapiuns (Ideflor-bio, 2009).

A medida que as consultas públicas na região para ouvir os diversos segmentos da sociedade envolvidos nas discussões sobre o uso sustentável dos recursos florestais eram realizadas, surgiam propostas de ordenamento das glebas oriundos dos 
diversos setores da sociedade civil organizada e do poder público local, o que foi determinante para a redução a 173.369,36 ha no PAOF 2010 e para 150.956,95 ha no PAOF 2011.

Logo um processo de ordenamento territorial foi sendo incorporado ao processo prévio de concessão florestal no conjunto de glebas Mamuru-Arapiuns, destacando a criação de 01 Projeto Estadual de Assentamento Sustentável (PEAS) e 06 Projetos Estaduais de Assentamento Agroextrativista (PEAEX), com área total de 293.226,96 ha, beneficiando 2. 237 famílias, conforme demonstrado no Quadro 1.

Quadro 1. Florestas públicas destinadas a projetos de assentamentos no Conjunto de Glebas Mamuru-Arapiuns.

\begin{tabular}{|c|c|c|c|c|}
\hline DENOMINAÇÃO & MODALIDADE & MUNICÍPIO & $\begin{array}{c}\text { N }{ }^{\circ} \text { FAMILIAS } \\
\text { ASSENTADAS }\end{array}$ & AREA (ha) \\
\hline Vista Alegre & PEAEX & Santarém & 33 & $5.719,04$ \\
\hline Curumucuri & PEAEX & Juruti & 1762 & $106.122,08$ \\
\hline Prudente- Monte Sinai & PEAEX & Juruti & 51 & $5.514,04$ \\
\hline Aruã & PEAEX & Santarém/Juruti & 36 & $23.632,04$ \\
\hline Mariazinha-Aracati & PEAEX & Santarém & 22 & $10.317,00$ \\
\hline Mamuru & PEAEX & Juruti/Aveiro & 300 & $133.850,48$ \\
\hline Repartimento & PEAS & Santarém & 33 & $8.072,28$ \\
\hline & TOTAL GERAL & & $\mathbf{2 2 3 7}$ & $\mathbf{2 9 3 . 2 2 6 , 9 7}$ \\
\hline
\end{tabular}

Fonte: adaptado do PAOF 2021/IDEFLOR-BIO.

Podemos inferir que as consultas públicas realizadas foram primordiais no processo de concessão florestal na região do conjunto de glebas Mamuru-Arapiuns, o que possibilitou dirimir conflitos que podiam ser gerados quando fossem implantadas as unidades de manejo florestal (UMF) na área, onde todos os assentamentos foram criados ou definidos para regularização fundiária entre 2008 e 2010, antes do lançamento do primeiro edital de concessão florestal ocorrido em 2011.

Ao considerar as Unidades de Conservação eletivas a concessão florestal, com planos de manejo aprovados em 2010, as Florestas Estaduais (FLOTAS) do Paru, Trombetas e Faro foram inseridas no PAOF 2011, neste documento foram considerados as consultas públicas realizadas, entre novembro de 2009 e janeiro de 2010, que resultou na exclusão das florestas de Faro e Trombetas do PAOF, pois nas consultas públicas as sobreposições territoriais na FLOTA Trombetas foram relatadas pela sociedade local. A FLOTA de Faro não apresentou restrições diretas no quesito sobreposição territorial, permanecendo como área prioritária no PAOF, todavia, a concessão florestal nunca foi implementada nesta Unidade de conservação.

O pioneirismo do estado do Pará na consolidação da concessão florestal é baseado em ser o único ente federativo a implantar concessão florestal em glebas públicas (florestas não destinadas ou florestas do tipo B) nestes 15 anos da lei de gestão de florestas públicas, tal qual único Estado da federação que concedeu florestas nos primeiros 5 anos da promulgação da referida lei, e atualmente mantem um total de 483.435,49 ha, com 09 contratos vigentes.

\subsection{Da gestão e monitoramento da concessão florestal}

A gestão e monitoramento ocorre por meio do acompanhamento do cumprimento das cláusulas contratuais do contrato de concessão florestal assinado entre órgão gestor (ente público) e concessionário (ente privado). Neste contrato constam todas as obrigações a serem cumpridas ao longo dos 30 anos de sua vigência, dentre as quais podemos destacar as obrigações administrativas, financeiras e socioambientais.

Para avaliar o cumprimento das cláusulas contratuais, o órgão gestor se utiliza da análise de Planos Operacionais Anuais (POAs), relatórios de produção, relatórios de gestão de recursos florestais, dados de produção no Sistema de Comercialização e 
Transporte de Produtos Florestais-SISFLORA 2.0 e a realização de visitas técnicas de monitoramento, no período de safra e embargo com objetivos diferenciados para cada período (Ideflor-Bio, 2019).

Com objetivo de garantir um bom andamento na gestão da concessão florestal, o órgão gestor empenhou-se na elaboração de normativas, diretrizes, notas técnicas, pareceres técnicos que visam orientar os concessionários ao cumprimento dos contratos de concessão florestal. Alguns desses documentos elaborados serão citados no desenvolvimento deste artigo.

Diante da efetiva gestão e monitoramento dos contratos de concessão florestal, assim como a lisura nos processos, a concessão florestal tornou-se uma referência no que tange a transparência e legalidade na produção de recurso florestal, por vezes garantido segurança nas negociações no mercado madeireiro. A transparência é transversal e fundamental em todos os processos, assim como a participação, vigilância e práticas de compra consciente por parte da sociedade (Moraes et al., 2021).

Conforme demonstrado no quadro 2, desde 2011 foram publicados 7 editais de concessão florestal, dos quais 4 editais resultaram na assinatura de 12 contratos, 9 contratos vigentes, resultaram de 4 editais, dos 7 editais publicados. São dados satisfatórios, diante à tantos fatores, que inviabilizaram o processo, como a limitação de florestas disponíveis, sobreposições territoriais, impugnações dos processos (suspensão de editais).

O Serviço Florestal Brasileiro assinou seus primeiros contratos de concessão florestal na FLONA Jamari em 2008, em Rondônia. E em 2010 assinou seus primeiros contratos no Pará, na FLONA Saracá-Taquera com 2 contratos somando 48.704 ha, e com a assinatura de mais 3 contratos somando 150.956,95 ha, que totalizaram 199.660,95 ha, a concessão florestal no Pará demonstrava que seria uma política florestal promissora que visse a garantir a produção madeireira estimada nos editais.

Contudo, ao passo que os órgãos gestores iniciavam a gestão e o monitoramento dos contratos, dificuldades em cumprilos eram apresentadas pelos concessionários. Os primeiros contratos assinados foram considerados pouco flexíveis, causando, possivelmente, a rescisão de alguns contratos de concessão florestal.

Quadro 2. Quadro demonstrativo dos atos administrativos referente a concessão florestal.

\begin{tabular}{|c|c|c|c|c|c|c|}
\hline ANO & $\begin{array}{c}\text { EDITAIS } \\
\text { PUBLICADOS }\end{array}$ & $\begin{array}{c}\text { CONTRATOS } \\
\text { ASSINADOS }\end{array}$ & $\begin{array}{c}\text { CONTRATOS } \\
\text { RESCINDIDOS }\end{array}$ & $\begin{array}{c}\text { ÁREA } \\
\text { CONCEDIDA } \\
\text { (ha) }\end{array}$ & $\begin{array}{c}\text { ÁREA } \\
\text { RESCINDIDA } \\
\text { (ha) }\end{array}$ & $\begin{array}{c}\text { ÁREA } \\
\text { CONCEDIDA } \\
\text { VIGENTE (ha) }\end{array}$ \\
\hline $\mathbf{2 0 1 1}$ & 2 & 3 & 0 & $150.956,95$ & 0,00 & \\
\hline $\mathbf{2 0 1 2}$ & 0 & 6 & 0 & $326.184,17$ & 0,00 \\
\hline $\mathbf{2 0 1 3}$ & 1 & 0 & 0 & 0,00 & 0,00 \\
\hline $\mathbf{2 0 1 4}$ & 0 & 1 & 0 & $24.965,52$ & 0,00 \\
\hline $\mathbf{2 0 1 5}$ & 0 & 1 & 0 & $41.954,47$ & 0,00 \\
\hline $\mathbf{2 0 1 6}$ & 1 & 0 & 0 & 0,00 & 0,00 \\
\hline $\mathbf{2 0 1 7}$ & 2 & 0 & 3 & 0,00 & $111.564,06$ & \\
\hline $\mathbf{2 0 1 8}$ & 1 & 1 & 0 & $50.938,44$ & 0,00 & \\
\hline $\mathbf{2 0 1 9}$ & 0 & 0 & 0 & 0,00 & 0,00 & \\
\hline $\mathbf{2 0 2 0}$ & 0 & 0 & 0 & 0,00 & 0,00 & \\
\hline $\mathbf{2 0 2 1}$ & 1 & 0 & 0 & 0,00 & 0,00 & \\
\hline TOTAL & $\mathbf{7}$ & $\mathbf{1 2}$ & $\mathbf{3}$ & $\mathbf{5 9 4 . 9 9 9 , 5 5}$ & $\mathbf{1 1 1 . 5 6 4 , 0 6}$ & $\mathbf{4}$ \\
\hline
\end{tabular}

Fonte: Adaptado da DGFLOP/IDEFLOR-Bio.

Podemos observar no Quadro 3, que a gestão e monitoramento de um contrato de concessão florestal, pode resultar em rescisão contratual, podendo ocorrer unilateralmente pelo órgão gestor por inexecução total ou parcial do contrato ou por iniciativa do concessionário. No caso da concessão florestal do Pará, em 2017 foram rescindidos 3 contratos de concessão 
florestal na FLOTA do Paru, por descumprimentos de cláusulas contratuais, dentre as quais podemos destacar inadimplência, irregularidade na execução do PMFS, inexecução do PMFS, descumprimento de prazos contratuais. As rescisões de contratos trazem prejuízos administrativos, financeiros e ambientais ao Estado, assim como causa desinteresse do setor madeireiro na participação dos processos licitatórios.

Quadro 3 - Demonstrativo dos contratos de concessão florestal no Pará.

\begin{tabular}{|c|c|c|c|c|c|}
\hline $\begin{array}{l}\text { GLEBA/ } \\
\text { FLOTA }\end{array}$ & UMF & LICITAÇÃO & CONCESSIONÁRIOS & ANO & $\begin{array}{c}\text { SITUAÇÃO } \\
\text { CONTRATUAL }\end{array}$ \\
\hline \multirow{3}{*}{$\begin{array}{l}\text { Mamuru } \\
\text { Arapiuns }\end{array}$} & I & \multirow{3}{*}{$\begin{array}{l}\text { Concorrência } \\
01 / 2011\end{array}$} & $\begin{array}{l}\text { LN GUERRA INDÚSTRIA E } \\
\text { COMERCIO DE MADEIRAS LTDA }\end{array}$ & 2011 & ATIVO \\
\hline & II & & $\begin{array}{c}\text { RONDOBEL INDÚSTRIA E } \\
\text { COMÉRCIO DE MADEIRAS LTDA }\end{array}$ & 2011 & ATIVO \\
\hline & III & & AMAZÔNIA FLORESTAL LTDA & 2011 & ATIVO \\
\hline \multirow{6}{*}{ Paru } & I & \multirow{6}{*}{$\begin{array}{l}\text { Concorrência } \\
\text { 02/2011 }\end{array}$} & $\begin{array}{l}\text { CEMAL COMÉRCIO ECOLÓGICO } \\
\text { DE MADEIRAS LTDA EPP }\end{array}$ & 2012 & ATIVO \\
\hline & II & & $\begin{array}{c}\text { MADEIREIRA SEGREDO LTDA } \\
\text { EPP }\end{array}$ & 2012 & ATIVO \\
\hline & III & & $\begin{array}{c}\text { RRX MINERAÇÃO E SERVIÇOS } \\
\text { LTDA - ME }\end{array}$ & 2012 & ATIVO \\
\hline & IV & & $\begin{array}{c}\text { SEMASA INDÚSTRIA, } \\
\text { COMÉRCIO E EXPORTAÇÃO DE } \\
\text { MADEIRAS LTDA }\end{array}$ & 2012 & RESCINDIDO \\
\hline & VIII & & $\begin{array}{c}\text { SEMASA INDÚSTRIA, } \\
\text { COMÉRCIO E EXPORTAÇÃO DE } \\
\text { MADEIRAS LTDA }\end{array}$ & 2012 & RESCINDIDO \\
\hline & IX & & $\begin{array}{c}\text { RRX MINERAÇÃO E SERVIÇOS } \\
\text { LTDA - ME }\end{array}$ & 2012 & ATIVO \\
\hline \multirow[t]{2}{*}{ Paru II } & $\mathrm{V}$ & \multirow{2}{*}{$\begin{array}{l}\text { Concorrência } \\
01 / 2013\end{array}$} & $\begin{array}{c}\text { BRUMARI TRANSPORTES E } \\
\text { SERVIÇOS FLORESTAIS LTDA- } \\
\text { ME }\end{array}$ & 2015 & RESCINDIDO \\
\hline & VII & & $\begin{array}{c}\text { RRX MINERAÇÃO E SERVIÇOS } \\
\text { LTDA - ME }\end{array}$ & 2014 & ATIVO \\
\hline Paru III & IVA & $\begin{array}{c}\text { Concorrência } \\
01 / 2018\end{array}$ & $\begin{array}{l}\text { BLUE TIMBER CONSULTORIA E } \\
\text { ASSESSORIA LTDA }\end{array}$ & 2018 & ATIVO \\
\hline
\end{tabular}

Dados: DGFLOP/IDEFLOR-Bio. Fonte: Elaborado pelos autores.

Assim como ocorreram rescisões contratuais na gestão do Estado do Pará, o Serviço Florestal Brasileiro, rescindiu 2 dos 19 contratos de concessão florestal federal firmados. Um dos contratos teve sua rescisão motivada por inadimplência contratual e o outro contrato teve como motivação o pedido de desistência por parte da concessionária. (SFB, 2020). O Gráfico 1 nos permite observar que proporcionalmente, o estado do Pará teve 19\% de suas áreas sob concessão florestal rescindida, se comparado ao serviço florestal brasileiro que teve $7 \%$ de suas rescindidas. 
Gráfico 1. Comparativo de áreas federais e estaduais sob concessão florestal.

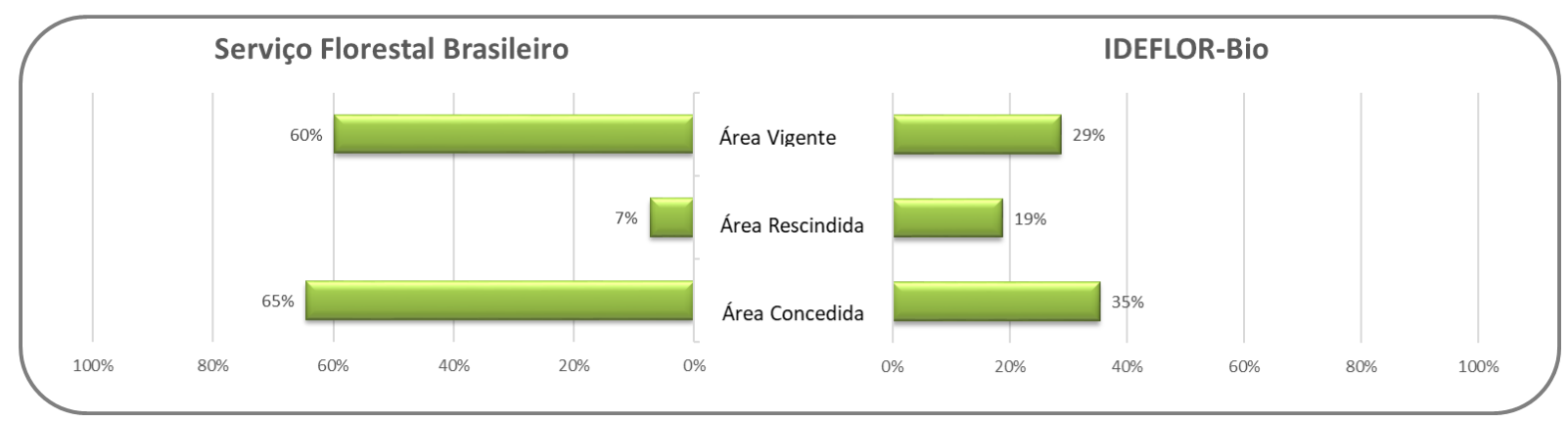

Dados: DGFLOP/IDEFLOR-Bio; SFB/MAPA. Fonte: Elaborado pelos autores.

Diante dos entraves identificados nos processos de concessão florestal, inclusive os que geraram as rescisões contratuais foram realizados ajustes que garantissem maior atratividade para a concessão florestal, da mesma forma que assegurasse um contrato de concessão florestal mais ajustável às condições apresentadas para melhor conduzir a sua execução.

Nos editais, podemos observar que os principais ajustes foram realizados a partir das redefinições dos indicadores técnicos para torna-los mais exequíveis, como a exclusão permanente dos indicadores de produtos e serviços explorados, que praticamente desobrigou os concessionários a explorar produtos não madeireiros, resíduos florestais e serviços florestais como esportes de aventura, visitação e observação da natureza, conforme previsto na legislação.

O indicador social "Investimento em infraestrutura e serviços para comunidade local" e o indicador de agregação de valor "Grau de processamento local do produto", se mantiveram em todos os editais publicados, devido à importância social e impacto direto causado pela exploração madeireira as comunidades locais. E a obrigatoriedade do concessionário em agregar valor ao produto explorado da floresta em área de influência da concessão florestal.

Nota-se, portanto, que os concessionários seguem um paradigma "cultural" do explorador madeireiro direcionado a exploração do produto madeira. Não conseguem valorizar a floresta, mesmo que lhes sejam apresentadas oportunidades de dinamizar o mercado florestal a partir da concessão florestal, erroneamente, ao logo do tempo, estigmatizado de "mercado madeireiro". Seria extremamente relevante que a mudança desse paradigma se fortalecesse no setor madeireiro e que a floresta passasse a ser valorada a partir do uso múltiplo dos recursos florestais.

Sobre a valoração do recurso florestal, uma avaliação correta dos valores de referências dos editais é necessária para evitar a subvalorização (potencialmente resultando em lucros inesperados para grupos privados e também no desperdício de recursos florestais naturais escassos) ou supervalorização (desencorajando licitações e/ou tornando a exploração sustentável não lucrativa (Rocha et al., 2006).

Segundo Santana et al. (2012) a política de concessão florestal subestima o valor socioeconômico e ambiental da floresta, uma vez que apenas a madeira em tora está em pauta, não havendo efetividade no aproveitamento dos resíduos de madeira, e não computa o valor dos produtos não madeireiros e os serviços ambientais da floresta assim como limita sua eficácia ao não estimular a participação de micro e pequenas empresas e das comunidades locais, organizadas em associações ou cooperativas.

Com base na experiência internacional, entretanto, está claro que as concessões florestais são complexas e sua implementação não é fácil. Também está bastante claro que as condições de investimento para concessões florestal ainda não são atraentes, especialmente considerando as condições adversas da Amazônia. Os altos investimentos iniciais e a burocracia governamental podem desencorajar os futuros concessionários (Azevedo-Ramos et al., 2015).

Há uma falta de interesse por parte das empresas madeireiras em relação a concessão, visto que o principal fator que limita a expansão das concessões florestais na Amazônia é a extração ilegal de madeira, que representou 44\% de toda a produção 
de madeira entre 2015 e 2016 no Estado do Pará. A madeira extraída legalmente, que requer investimentos substanciais de longo prazo em maquinários, recursos humanos e infraestrutura, entre outros, concorre de forma bastante desigual com a extração ilegal, o que reduz os preços de mercado devido ao baixo custo de produção associado à ausência de altos investimentos (Vidal et al., 2020; Sist et al., 2021).

Todo o esforço realizado para a implantação da política de concessão florestal poderá ser inútil se o mercado de madeiras tropicais continuar sendo inundado com produtos mais baratos, gerados a partir de uma produção ilegal, uma vez que o produto advindo de áreas de manejo florestal sustentável não consegue competir por preço com o produto que apresenta origem ilícita (Azevedo-Ramos et al., 2015; Rodrigues et al., 2020). A competição entre atividades ilegais fora das concessões e o manejo florestal sustentável dentro das concessões implica em grandes perdas econômicas para o governo brasileiro (Santos de Lima et al., 2018).

Apesar de, em 2018 o total de área licenciada ter sido baixa em relação à média, houve uma produção de madeira de 125.402,89 m³ , oriundas de áreas licenciadas do ano anterior, pois as autorizações de exploração florestal (AUTEF) no estado do Pará tem validade de 2 anos. Outra informação que o gráfico 2 apresenta está no decréscimo de área licenciada entre os anos de 2016 e 2017, que ocorreu devido as rescisões contratuais em 2017.

Para o licenciamento das áreas de concessão florestal a Instrução Normativa (SEMAS/PA) n ${ }^{\circ}$ 05, de 10 de setembro de 2015, assegura ao concessionário uma distinção em relação aos PMFS privados, possibilitando um processo mais simplificado, seguindo um fluxo diferenciado no órgão licenciador, conjuntamente com a diretriz elaborada em 2012 (atualizada em uma $2^{\mathrm{a}}$ edição em 2014) pelo órgão gestor em "Diretrizes para elaboração do plano operacional anual (POA)", visando dar mais celeridade ao processo de licenciamento.

Os procedimentos citados acima foram, inclusive, mencionados no processo de auditoria TC 046.126/2012-0 que teve como escopo avaliar o processo de concessão florestal federal. Segundo o relator do processo, a atuação do Instituto de Desenvolvimento Florestal e da Biodiversidade do Estado do Pará - IDEFLOR-Bio, como interlocutor entre os concessionários e o órgão licenciador, propiciava maior agilidade no andamento ao processo de licenciamento, bem como a adoção de procedimentos que tem contribuído para o alcance de resultados mais céleres ao processo de concessão florestal (TCU, 2012).

Gráfico 2. Total de área (ha) de concessão florestal licenciada por ano.

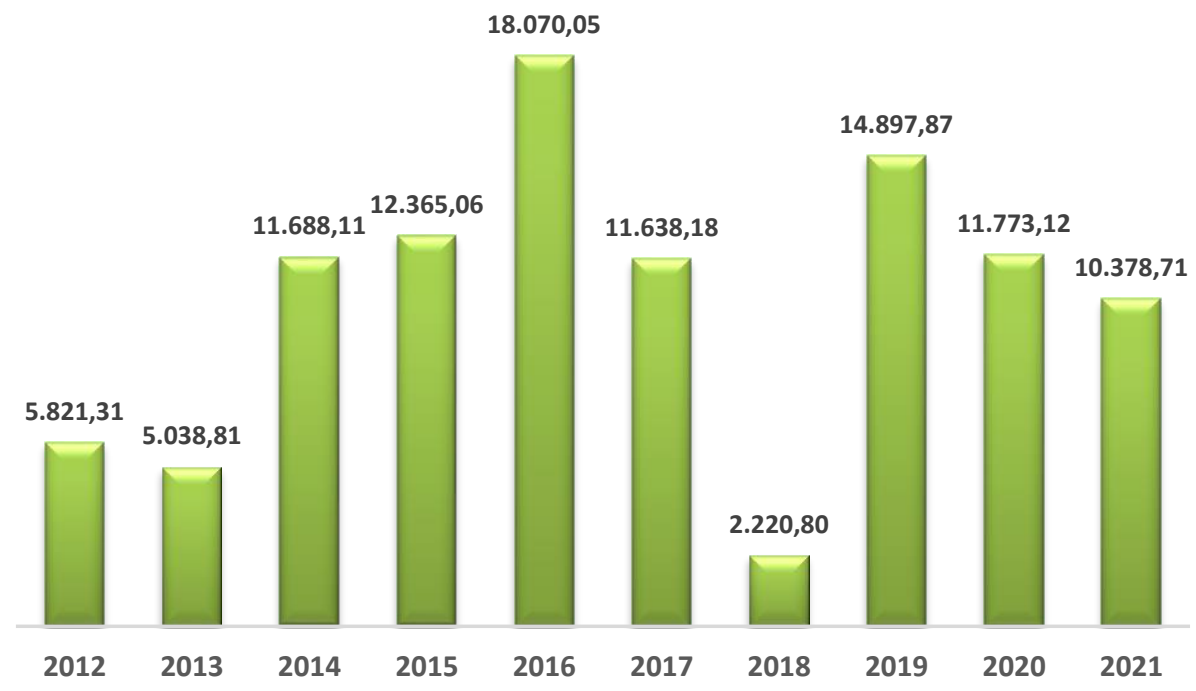

Base de Dados: DGFLOP/IDEFLOR-Bio. Fonte: Elaborado pelos autores. 
Conforme previsto em contrato de concessão florestal, o concessionário tem um prazo de até 12 meses após a assinatura do contrato para protocolar o PMFS no órgão licenciador e até 24 meses para a início das atividades de exploração dos recursos florestais. Os concessionários que assinaram contratos em 2011, iniciaram de imediato os trâmites para elaboração de Plano de Manejo Florestal Sustentável (PMFS) e Planos de Operacionais Anuais (POA's) e logo no ano seguinte estavam com suas respectivas Licenças de Atividades Rurais (LAR), assim como Autorizações de Exploração Florestal (AUTEF) aprovadas.

Para Bliacheris (2011) a ideia do manejo permeia de forma tão absoluta a Lei de Gestão de Florestas Públicas que os próprios conceitos de produtos4 e serviços5 florestais os consideram como decorrentes do manejo florestal e o fomento ao manejo florestal é consagrado entre os princípios da gestão das florestas públicas.6 Há uma clara mensagem do legislador: não existe outra possibilidade de produção em floresta pública senão de forma sustentável e o instrumento válido para atingi-la é o manejo florestal.

Gráfico 3. Gráfico da relação Volume autorizado x Volume produzido.

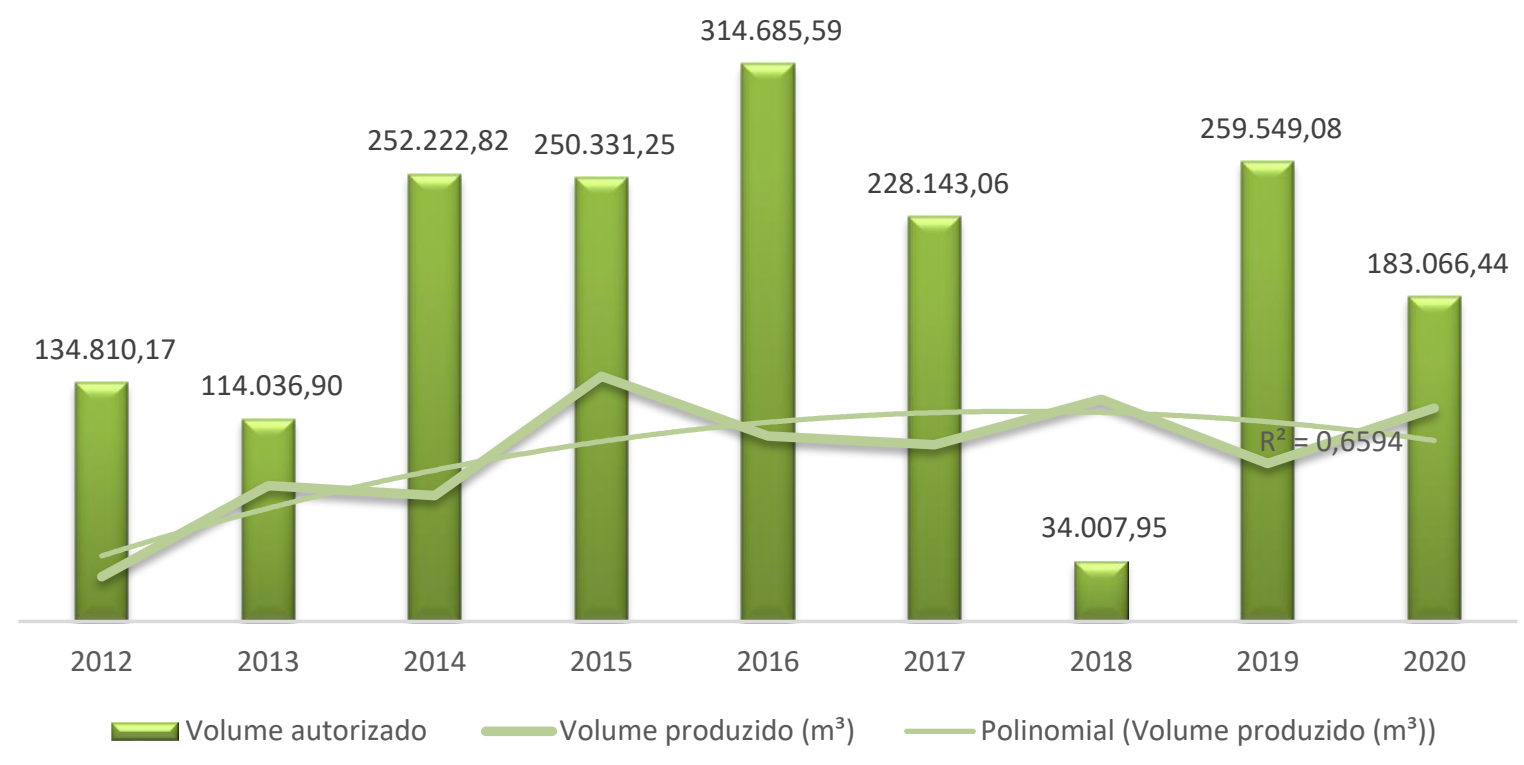

Base de Dados: DGFLOP/IDEFLOR-Bio. Fonte: Elaborado pelos autores.

Como o ciclo de corte dos contratos sob a gestão do estado é de 30 anos, e considerando a estimativa de produtividade anual de $0,86 \mathrm{~m}^{3} / \mathrm{ha} / \mathrm{ano}$. Podemos observar no gráfico 3 que em todos os anos houve autorização para exploração estimativa de capacidade produtiva de $25,8 \mathrm{~m} 3 / \mathrm{ha}$. Ainda assim, o gráfico mostra que que mais se produziu na concessão florestal foi em 2015 , com uma produção madeireira de $138.377,30 \mathrm{~m}^{3}$. Nesse gráfico podemos ainda verificar que nem sempre o que é autorizado no ano é o que é produzido, como em 2018, que o volume autorizado é inferior ao volume produzido. Em relação a capacidade produtiva, a média de alcance das concessionárias não ultrapassou $20 \mathrm{~m}^{3} / \mathrm{ha}$.

Essa capacidade produtiva também pode estar relacionada a dificuldade de inserção de espécies com pouca saída no mercado madeireiro. Neste artigo, não discutirei a diversidade de espécies exploradas, contudo o concessionário tem um limite máximo de exploração de espécies por AUTEF, que geralmente adota como estratégia atingir pelo menos $30 \mathrm{~m}^{3}$ de tora por ano das espécies sem interesse comercial, resultado na produtividade mencionada no parágrafo anterior.

Ao realizar simulações em 27 cenários diferentes usando combinações de proporção inicial de volume comercial, intensidade de extração e duração do ciclo de corte, aplicados a concessão florestal, Sist et al., (2021) argumentaram que o sistema de concessão atual não será capaz de suprir a demanda de madeira sem reformas substanciais nas práticas de manejo 
florestal natural e no setor da indústria madeireira. Argumentaram ainda que fontes alternativas de madeira, incluindo plantações vinculadas a iniciativas de restauração florestal, devem ser promovidas.

O gráfico 4 apresenta a relação do volume de madeira produzido com a arrecadação anual, e conforme podemos observar a produção não está alinhada com a arrecadação. Essa dissociação entre o volume de madeira produzida e a arrecadação está atribuída a inadimplência. A inadimplência, geralmente, justificada pela crise no mercado interno e instabilidade do mercado internacional, que desestabilizou a demanda de produto florestal.

Para minimizar a inadimplência e as sanções administrativas e ambientais, o IDEFLOR-Bio, a partir de 2017, adotou a estratégia de executar Planos Emergenciais de Pagamentos, que parcelava o débito em parcelas pagas a cada 2 meses. Mas ainda assim, a inadimplência se mantinha.

Então, em 2018, aprovou o Programa de parcelamento de débitos não tributários oriundos dos contratos de concessão florestal do Estado do Pará, esse programa está vigente e visa manter viável economicamente os contratos de concessão, para que não haja necessidade de rescisão dos mesmos, nem desistência dos concessionários.

No Gráfico 4, a linha de tendência linear para a arrecadação (R\$), com ajuste de valor $\operatorname{Ra}^{2}: 0,77$ nos mostra que a arrecadação aumentou e teve pouca variação, no período de 2011 a 2020, mesmo com a queda na arrecadação em 2017 causada pela inadimplência. Já a linha de tendência para volume $\left(\mathrm{m}^{3}\right)$, com ajuste de valor $\mathrm{Rv}^{2}$ : 0,58 nos mostra uma instabilidade na produção da madeira no período observado. $\mathrm{O}$ aumento na arrecadação neste período se deu, principalmente, pelas estratégias de gestão adotada pelo IDEFLOR-Bio de manter a adimplência dos contratos de concessão florestal.

Gráfico 4. Gráfico da relação do Volume produzido $\left(\mathrm{m}^{3}\right)$ x Arrecadação (R\$).

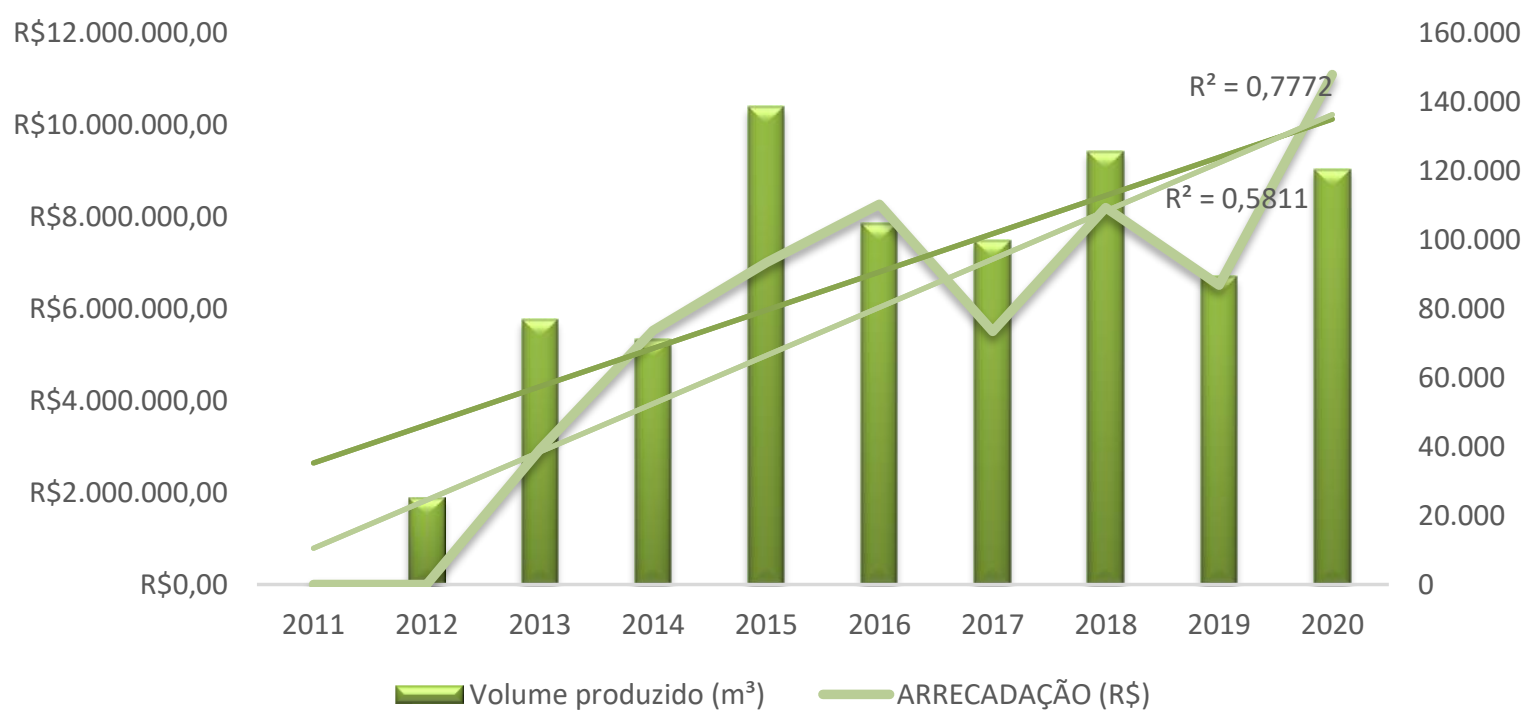

Base de Dados: DGFLOP/IDEFLOR-Bio. Fonte: Elaborado pelos autores.

A viabilidade econômica da concessão florestal pode contribuir efetivamente para combinar os objetivos de maximização do lucro das empresas com o objetivo da sociedade de minimizar o impacto ambiental das alternativas econômicas de uso do solo no Pará, especificamente na região do Baixo Amazonas, onde foram implantados os contratos de concessão florestal pelo estado do Pará (Santana et al., 2012).

No monitoramento do contrato, há a obrigação específica do órgão gestor em avaliar, anualmente, o cumprimento das propostas técnicas, conforme os critérios de menor impacto ambiental, os maiores benefícios sociais diretos, a maior eficiência e a maior agregação de valor ao produto ou serviço florestal, conforme determinado na Lei Federal no 11.284/2006. 
Os indicadores técnicos são apresentados em cada edital de concessão florestal e eles são o grande diferencial técnico em relação aos PMFS de áreas privadas. Eles fazem parte da etapa de "julgamento de propostas técnicas”, em que cada licitante deve apresentar como proposta, dentro dos parâmetros estabelecidos em edital. Esses indicadores devem atender a critérios que são: a. o menor impacto ambiental; b. os maiores benefícios sociais diretos; c. a maior eficiência e d. a maior agregação de valor ao produto ou serviço florestal na região da concessão (Brasil, 2006).

Neste artigo vou me ater ao critério maior benefício social, o qual a concessionária tem a obrigação de investir junto as comunidades locais, um valor em reais por hectare da área total da unidade de manejo ( $\mathrm{R} \$ \mathrm{ha})$, determinado no ato do processo licitatório apresentado na forma de proposta técnica. Para a avaliação do indicador o IDEFLOR-Bio elaborou diretriz específica, que define principalmente os meios de verificação, como a verificação de extrato de conta bancária onde houve o depósito do recurso, atas das reuniões realizadas com as comunidades e relatório descrevendo a execução do recurso, conforme demanda da comunidade.

Gráfico 5. Valores em R \$ destinados ao Indicador Social A2.

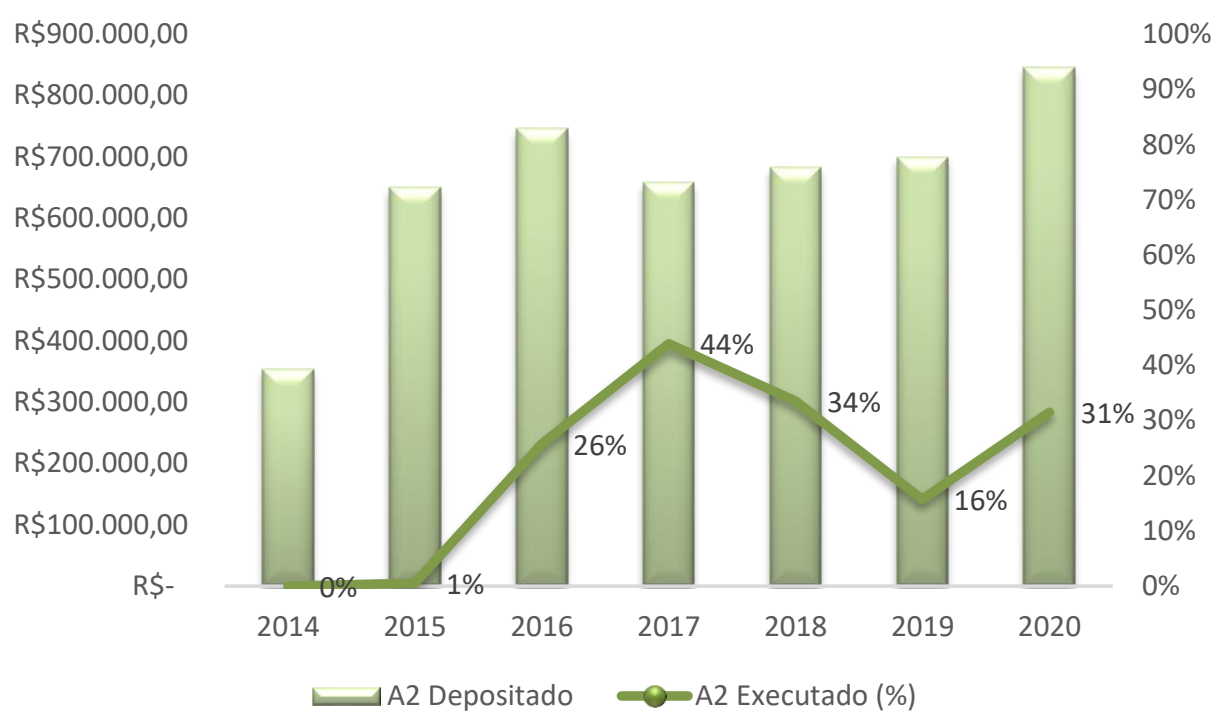

Base de Dados: DGFLOP/IDEFLOR-Bio. Fonte: Elaborado pelos autores.

Conforme dados apresentados no gráfico 5, podemos observar que os valores referentes ao cumprimento parcial do indicador A2 tem sido depositado anualmente, entretanto, observa-se uma instabilidade na aplicação desses recursos nas comunidades. Pode haver uma fragilidade procedimental neste indicador social, o qual deve ser o gerador dessa execução parcial, cuja responsabilidade é do concessionário de aplicar os recursos conforme demanda das comunidades.

Os indicadores sociais como investimento nas comunidades locais (Gráfico 5), geração de emprego local, participação da comunidade local na exploração de produtos na unidade de manejo são pontos fortes para alcançar a melhoria de qualidade de vida dessas populações locais, que são afetadas diretamente pela concessão florestal.

O Concessionário tem a obrigação financeira de pagar pelo $\mathrm{m}^{3}$ de madeira explorada das áreas de concessão florestal. Esse recurso financeiro é destinado ao FUNDEFLOR, um fundo de natureza contábil, com autonomia administrativa e financeira, vinculado ao IDEFLOR-Bio. Cabe ao FUNDEFLOR destinar os recursos financeiros arrecadados, onde 30\% é destinado ao IDEFLOR-BIO; $30 \%$ aos municípios abrangidos pela concessão florestal e 40\% destinado a execução de projetos aprovados pelo conselho deliberativo do FUNDEFLOR. 
Gráfico 6. Distribuição dos Valores em R \$ arrecadados oriundos do pagamento do recurso florestal explorado.

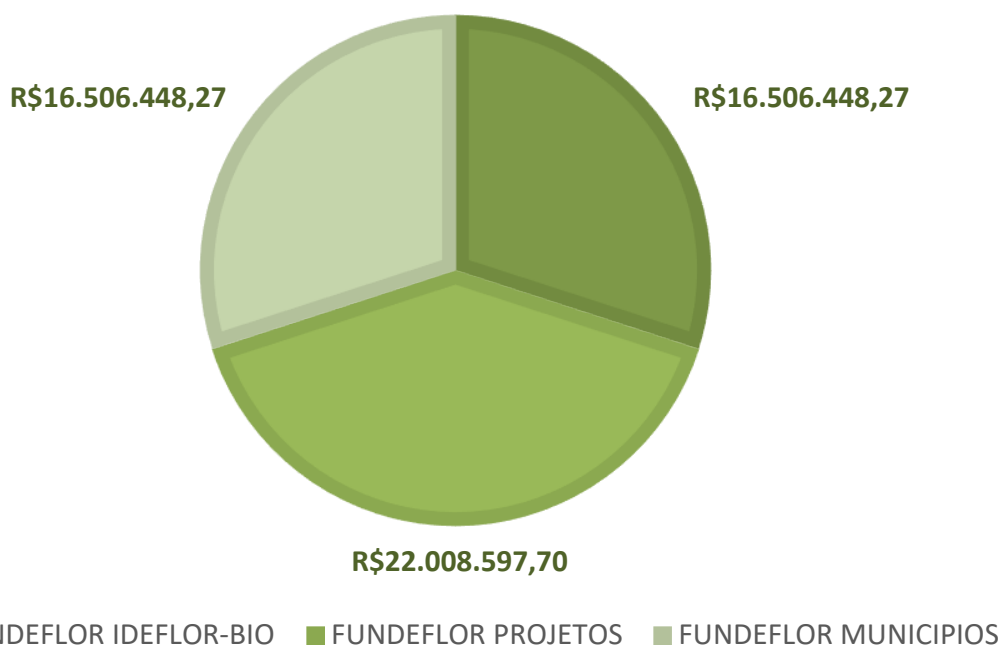

Base de Dados: DGFLOP/IDEFLOR-Bio. Fonte: Elaborado pelos autores.

A arrecadação total oriunda da concessão florestal (2012-2020), conforme dados do IDEFLOR-Bio foi de R\$ 55.021.494,25 e como demonstra o gráfico 6 foram repassados $\mathrm{R} \$ 16.506 .448,27$ ao IDEFLOR-Bio, $\mathrm{R} \$ 22.008 .597,70$ permanecem no FUNDEFLOR para aplicação nos projetos e $\mathrm{R} \$ 16.506 .448,27$ repassados aos municípios.

Do valor repassado aos municípios, o município de Aveiro arrecadou $\mathrm{R} \$ 3.884 .679,35$; Juruti arrecadou $\mathrm{R} \$$ 2.539.210,23; Santarém arrecadou $\mathrm{R} \$ 4.038 .849,11$; Almeirim arrecadou $\mathrm{R} \$ 4.548 .003,90$ e Monte Alegre arrecadou $\mathrm{R} \$$ 1.417.346,30. Esses valores são distribuídos proporcionalmente a área de concessão florestal que compreende o município, o que determina a distinção dos valores (Ideflor-Bio, 2021).

Devido à complexidade da gestão dos contratos de concessão florestal, com a função de gerir questões administrativas, financeiras, contábil e técnica de forma integrada, garantir transparência e controle social do processo, garantir uma eficiente organização das informações, garantir acesso rápido e ordenado das informações referente aos contratos aos gestores e concessionários e possibilitar maior agilidade no controle e acompanhamento dos processos, o IDEFLOR-BIO implantou em 2018, o SGC - Sistema de Gestão de Concessão.

O SGC potencializa o fluxo de informações e de demandas entre o Instituto e as empresas com contratos de concessão ativos. O sistema visa aprimorar a comunicação entre os concessionários e o IDEFLOR-Bio. A "Central de Comunicação, por exemplo, torna o trabalho burocrático mais ágil e eficaz, bem como possibilita um maior controle das obrigações e prazos contratuais". A nova ferramenta facilita o controle e o cumprimento de prazos e cláusulas contratuais (Ideflor-Bio, 2019).

\section{Considerações Finais}

Em virtude do que foi apresentado, podemos concluir que, mesmo diante de inúmeras situações adversas enfrentadas, a atuação do IDEFLOR-Bio na gestão tem como propósito garantir que a concessão florestal se mantenha como uma política florestal efetiva e eficiente. Os resultados apresentados demonstram que a concessão florestal busca alcançar os benefícios ambientais, sociais e econômicos, por meio da gestão e monitoramento das áreas licenciadas anualmente, produção madeireira compatível com a potencialidade da floresta, gerando arrecadação financeira ao Estado do Pará para ações voltadas a gestão das florestas públicas geridas pelo IDEFLOR-Bio. 
O IDEFLOR-Bio tem um papel crucial na gestão de florestas públicas do estado do Pará, onde se destaca seu relevante pioneirismo na concessão florestal, além de sua atuação no desenvolvimento da cadeia florestal do estado, na gestão de 27 unidades de conservação, na gestão da sociobiodiversidade, e execução do Fundo de Desenvolvimento Florestal (FUNDEFLOR), apresentando resultados significativos que alcançam públicos diversos, dialogando do setor madeireiro às comunidades locais e tradicionais, mesmo em condições institucionais não favoráveis, no sentido de escassez de recursos humanos, financeiros e tecnológicos.

Ainda há muito a avançar e aprimorar na condução da concessão florestal no estado do Pará: como abordar novas modalidades de concessão florestal; garantir uso de tecnologias que auxiliem no monitoramento das unidades de manejo; apoiar as pesquisas cientificas voltadas a área florestal e ambiental; incentivar os concessionários ao uso múltiplo dos recursos florestais e estimula-los a terem uma visão ampla de mercado de espécies potencialmente comerciais.

E levando-se em consideração que as florestas públicas de interesse futuro para concessão florestal apresentam entraves, dentre as quais destacamos a indispensável revisão dos planos de manejo já existentes e a elaboração do plano de manejo para as FLOTAS. Porém a simples revisão ou elaboração de planos de manejo não garante a concessão florestal. Por isso, imprescindível que o IDEFLOR-Bio, adote novas abordagens de concessão, tendo como exemplo, a concessão para recuperação ou recomposição florestal, que garanta produto ao mercado consumidor de floresta plantada, bem como garantir que a concessão florestal esteja associada aos objetivos previstos no Plano Estadual Amazônia Agora (PEAA) e na Política Estadual sobre Mudanças Climáticas do Pará (PEMC/PA), que promovam um desenvolvimento econômico alinhado ao aumento do estoque de carbono florestal no estado do Pará.

Ademais, com esta pesquisa observa-se a necessidade de pesquisas futuras que abordem a viabilidade de outras modalidades de concessão florestal na Amazônia, assim como estudos que visem avaliar os contratos vigentes para futuras adequações que garantam a longevidade da concessão florestal no estado do Pará.

\section{Agradecimentos}

Ao Instituto de Desenvolvimento Florestal e da Biodiversidade do estado do Pará pela disponibilidade de dados e apoio nesta pesquisa.

\section{Referências}

Azevedo-Ramos, C., Silva, J. N. M., \& Merry, F. (2015). The evolution of Brazilian forest concessions. Elementa: Science of the Anthropocene, 3(48), 1-8. https://doi.org/10.12952/journal.elementa.000048

Bliacheris, M. W. (2011). Manejo florestal sustentável - uma perspectiva jurídica. Revista da AGU (29) ano 10 . https://www.academia.edu/55607566/Manejo_Florestal_Sustent\%C3\%A1vel_Uma_Perspectiva_Jur\%C3\%ADdica

Brasil (2000). Lei $n^{\circ}$ 9.985, de 18 de julho de 2000. Institui o Sistema Nacional de Unidades de Conservação da Natureza e dá outras providências. http://www.planalto.gov.br/ccivil_03/leis/19985.htm

Brasil (2006). Lei $n^{\circ}$ 11.284, de 02 de março de 2006. Dispõe sobre a gestão de florestas públicas para a produção sustentável. http://www.planalto.gov.br/ccivil_03/_ato2004-2006/2006/lei/111284.htm

Cardoso, K. dos S. (2018). Participação social e a gestão de florestas públicas no estado do Pará. II Congresso Brasileiro de gestão. Revista UNAMA. 39 - 53. http://revistas.unama.br/index.php/coloquio/article/view/1139

GIL, A. C (2021). Como elaborar projetos de pesquisa (6a ed.).: Atlas.

Mesquita, J. C. (2014). Estratégias de Controle Social de Unidades de Conservação: Desafios para uma Gestão Democrática e Participativa. [Dissertação de Mestrado em Gestão de Áreas Protegidas na Amazônia, INPA]. Repositório institucional do INPA. https://bdtd.inpa.gov.br/handle/tede/2506

Melo Júnior, L., Tourinho, M., Sayago, D., \& Palha, M. (2013). Uso de recursos naturais por comunidades ribeirinhas amazônicas: bases para as políticas de concessões florestais. Novos Cadernos NAEA, 16(1). http://dx.doi.org/10.5801/ncn.v16i1.1067

Moraes I, Azevedo-Ramos C., \& Pacheco J (2021) Public Forests Under Threat in the Brazilian Amazon: Strategies for Coping Shifts in Environmental Policies and Regulations. Front. For. Glob. Change 4:631756. 10.3389/ffgc.2021.631756 
Muniz, T. F; \& Pinheiro, A. S. O. (2019). Concessão florestal como instrumento para redução de exploração ilegal madeireira em Unidades de Conservação em Rondônia. Revista FAROL, 8 (8), 121-142. http://www.revistafarol.com.br/index.php/farol/article/view/123

IDEFLOR-BIO (2009). Plano anual de outorga florestal 2008/2009. Instituto de Desenvolvimento florestal e da biodiversidade https://ideflorbio.pa.gov.br/concessao-florestal/paof/

IDEFLOR-BIO (2011). Plano anual de outorga florestal 2011. Instituto de Desenvolvimento Florestal e da Biodiversidade https://ideflorbio.pa.gov.br/concessao-florestal/paof/

IDEFLOR-BIO (2019). Relatório Anual de Gestão 2018. Instituto de Desenvolvimento Florestal e da Biodiversidade. https://ideflorbio.pa.gov.br/relatorios-deatividade/

IDEFLOR-BIO (2020). Relatório Anual de Gestão 2019. Instituto de Desenvolvimento Florestal e da Biodiversidade. https://ideflorbio.pa.gov.br/relatorios-deatividade/

IDEFLOR-BIO (2021). Relatório Anual de Gestão 2020. Instituto de Desenvolvimento Florestal e da Biodiversidade. https://ideflorbio.pa.gov.br/relatorios-deatividade/

IDEFLOR-BIO (2021). Plano anual de outorga florestal 2021. Instituto de Desenvolvimento Florestal e da Biodiversidade. https://ideflorbio.pa.gov.br/concessao-florestal/paof/

Para (2007). Lei n. 6.963, de 16 de abril de 2007. Dispõe sobre a criação do Instituto de Desenvolvimento Florestal do estado do Pará e do Fundo estadual de desenvolvimento florestal e dá outras providências. https://ideflorbio.pa.gov.br/legislacao-estadual/

Para (2015). Lei n. 8.096, de 01 de janeiro de 2015. Dispõe sobre a estrutura da Administração Pública do Poder Executivo Estadual, e dá outras providências. http://www.seplan.pa.gov.br/sites/default/files/lp2015_08096_lei_8.096_de_1.1.2015.pdf.

Para (2020). Lei $n^{\circ}$ 9.048, de 29 de abril de 2020. Institui a Política Estadual sobre Mudanças Climáticas do Pará (PEMC/PA), e dá outras providências. https://www.semas.pa.gov.br/legislacao/files/pdf/4093.pdf

Para (2020). Decreto $n^{\circ}$ 941, de 03 de agosto de 2020. Institui o Plano Estadual Amazônia Agora (PEAA), cria o Comitê Científico do Plano e o Núcleo Permanente de Acompanhamento do Plano e dá outras providências. https://www.semas.pa.gov.br/legislacao/files/pdf/8457.pdf

Pereira, J., Moura, S., Mesquita, J., Bandeira, L. \& Veríssimo, A. (2020) Áreas Protegidas do Norte do Pará: história de ocupação, desenvolvimento e ordenamento territorial. Belém: Imazon. https://imazon.org.br/publicacoes/areas-protegidas-do-norte-do-para-historia-de-ocupacao-desenvolvimento-eordenamento-territorial/

Rocha, K., Moreira, A. R. B, Reis, E. J., \& Carvalho, L. (2006). The market value of forest concessions in the Brazilian Amazon: a Real Option approach. Forest Policy and Economics, 8, 149 - 160. https://doi-org.ez3.periodicos.capes.gov.br/10.1016/j.forpol.2004.05.008

Rodrigues, M. I., Souza, Álvaro N. de, Joaquim, M. S., Lustosa Junior, I. M., \& Pereira, R. S. (2020). Concessão florestal na Amazônia brasileira. Ciência Florestal, 30(4), 1299-1308. https://doi.org/10.5902/1980509821658

Santana, A. C., Santana, Á. \& Santos, M. A. (2011). Influência do desmatamento no mercado de madeira em tora da região Mamuru-Arapiuns, Sudoeste do Pará. Revista de Ciências Agrárias. 54. 44-53. 10.4322/rca.2011.037.

Santana, A. C. de, Santos, M. A. S dos, Santana, A. L. de, \& Yared, J. A. G. (2012). O valor econômico da extração manejada de madeira no Baixo Amazonas, estado do Pará. Revista Árvore, v.36, n.3, p.527-536, 2012. https://doi.org/10.1590/S0100-67622012000300015

Santos de Lima L, Merry F, Soares-Filho B, Oliveira Rodrigues H, dos Santos Damaceno C, \& Bauch M A (2018). Illegal logging as a disincentive to the establishment of a sustainable forest sector in the Amazon. PLoS ONE 13 (12): e0207855. https://doi.org/10.1371/journal.pone.0207855

SFB (2021). Plano anual de outorga florestal 2021 Serviço Florestal Brasileiro. https://www.florestal.gov.br/plano-anual-de-outorga-florestal/63-concessoesflorestais/1939-plano-anual-de-outorga-florestal-publicacoes

SFB (2021). Relatório de gestão de florestas públicas 2020. Serviço Florestal Brasileiro. https://www.florestal.gov.br/relatorios-de-gestao

Sist, P., Piponiot, C., Kanashiro, M., Pena-Claros, M., Putz, F. E., Schulze, M., Veríssimo, A., \& Vidal, E. (2021). Sustainability of Brazilian forest concessions. For. Ecol. Manage. 496, 119440. https://doi-org.ez3.periodicos.capes.gov.br/10.1016/j.foreco.2021.119440

Soares, C. C., Canto, O., \& Bastos, R. Z. (2017). Gestão de Florestas Públicas por meio de Concessão Florestal e Conflitos, no Estado do Pará. Org In: Canto, O., Condurú, M. T., Moraes, S. C. (Eds.), Gestão Ambiental na Amazônia Conflitos, limites e possibilidades. (pp. 12-40). NUMA/UFPA.

TCU (2014). Auditoria operacional. Concessões florestais. Recomendações. Comunicações. Arquivamento. Tribunal de Contas da União (TCU 04612620120, Relator: Weder de Oliveira. Data de Julgamento: 20/08/2014). https://tcu.jusbrasil.com.br/jurisprudencia/315623881/4612620120 